\section{Privatização da gestão do sistema municipal de saúde por meio de Organizações Sociais na cidade de São Paulo, Brasil: caracterização e análise da regulação}

\author{
Privatization of health care management through \\ Social Organizations in the city of São Paulo, \\ Brazil: description and analysis of regulation
}

\author{
La privatización de la gestión del sistema de salud \\ a través de Organizaciones Sociales en la ciudad \\ de São Paulo, Brasil: caracterización y análisis \\ de la regulación
}

\begin{abstract}
The article describes and discusses privatization of the municipal health system in São Paulo, Brazil, from an administrative and political perspective. The methodology consisted of a literature review and analysis of legislation and public documents. The study showed that although legislation governing the so-called "Social Organizations" (OS) in Brazil dates to the year 2006, half of the administrative privatization is still regulated by a previous provisional instrument in the form of an "agreement" ("convênio" in Portuguese). In 2011, 61\% of services were administered by private organizations, which received $44 \%$ of the health budget in 2012. The twenty participating organizations include five of the ten largest health care companies in Brazil. Inspection agencies have detected flaws in the management contracts, but the "agreements" (convênios) are subject to less rigorous control and have proven invisible to inspection. Finally, the legal framework is unstable. The study uses the experience in São Paulo as the basis for discussing the political versus technical nature of private management in the Brazilian Unified National Health System (SUS).
\end{abstract}

Health Management; Health Care Reform; Privatization
Henrique Contreiras

Gustavo Corrêa Matta ${ }^{1}$

\section{Resumo}

Este trabalho caracteriza e discute a privatização da gestão do sistema municipal de saúde na cidade de São Paulo, Brasil, com base em uma perspectiva administrativista e política. A metodologia consistiu em levantamento bibliográfico e análise de legislação e documentos públicos. A pesquisa demonstrou que embora a lei de Organizações Sociais (OS) seja de 2006, metade da privatização da gestão ainda é regulada por um ajuste provisório anterior, o convênio. Em 2011, $61 \%$ dos serviços eram geridos por entidades privadas que, em 2012, receberam 44\% do orçamento da saúde. As vinte entidades envolvidas incluem cinco dos dez maiores grupos privados de serviços médicos do país. Órgãos fiscalizadores evidenciam falhas de controle nos contratos de gestão, mas os convênios, que apresentam controle mais frágil, têm sido invisiveis à fiscalização. Por fim, o marco legal é instável. Valendose da experiência paulistana, discute-se o caráter político vs. técnico da regulação da gestão privada no Sistema Único de Saúde (SUS).

Gestão em Saúde; Reforma dos Serviços de Saúde; Privatização 


\section{Introdução}

Nos anos 1980, em um contexto de crise econômica mundial e globalização, ganharam legitimidade teses de que o crescimento econômico e a consolidação da democracia exigiriam, por um lado, a redução da intervenção estatal e dos gastos públicos e, por outro, o fortalecimento do mercado e da sociedade civil. Essas foram as bases teóricas de uma onda de reformas do Estado nos países centrais, caracterizadas por ajustes macroeconômicos e flexibilização administrativa. O movimento repercutiu de forma importante nos sistemas de saúde - então pressionados pelo encarecimento da tecnologia médica e pelo envelhecimento populacional. As reformas do setor se basearam em medidas de estabilização de custos como a limitação do escopo do seguro social e, posteriormente, em reformulações organizacionais visando à eficiência microeconômica 1 .

A disseminação das reformas para países periféricos foi em grande parte mediada por organismos internacionais, que as incluíram em seu rol de condicionamentos para empréstimos. Para o setor saúde recomendavam-se a redução do financiamento estatal e o aumento da provisão privada. A incorporação das reformas pelos diversos países foi heterogênea e se deu em função da vulnerabilidade dos governos em relação às exigências, da robustez do mercado ou da existência de projetos políticos alternativos à privatização 2 .

No Brasil, o marco institucional do movimento foi a criação, em 1995, do Ministério da Administração e Reforma do Estado, cujo projeto foi sintetizado no Plano Diretor da Reforma do Aparelho do Estado (PDRAE). O documento diagnosticou a administração burocrática como ineficiente e patrimonialista e prescreveu estratégias para os diferentes setores do Estado. No plano econômico, defendeu-se a desregulação do mercado, a desestatização das empresas públicas e a concessão de serviços públicos comerciais e industriais para empresas privadas. No plano social, propôs-se delegar a gestão dos serviços públicos para entidades privadas sem fins lucrativos, denominadas Organizações Sociais (OS), identificadas com o fortalecimento da sociedade civil e referidas como "setor público não-estatal”. O Estado, nesse caso, abriria mão de seu papel de executor de políticas públicas para assumir uma função de regulador.

Em 1998, a Lei no 9.637 criou a figura das OS na esfera federal para os setores de saúde, ensino, ciência, tecnologia, meio ambiente e cultura. Tecnicamente, OS é uma qualificação conferida pelo Estado a uma entidade privada que, de posse deste título, pode estabelecer com o poder pú- blico uma parceria regulada por um instrumento chamado contrato de gestão, por meio do qual lhe é delegada a administração de uma instituição pública. Tanto qualificação quanto contratação dispensam licitação. Segundo pesquisa do Ministério do Planejamento, Orçamento e Gestão (MPOG) com dados de 2009 3, alguns estados e municípios promulgaram nos anos seguintes suas próprias leis de OS. Essas se basearam na Lei Federal, mas incluíram, de forma heterogênea, novos procedimentos como processos seletivos para as entidades ou comissões externas de acompanhamento. A saúde foi a principal área de aplicação do modelo (95\% das leis). Foram contabilizadas 15 leis estaduais e 41 municipais. No entanto, era baixo o número de OS contratadas por esfera: seis na federal, 28 na estadual e 15 na municipal. Tais dados demonstram que, quando comparado com outras estratégias do PDRAE, massivamente postas em prática, o projeto das OS não foi bem-sucedido enquanto uma diretriz nacional.

Tal atrofia pode ser explicada em parte pela existência de uma agenda alternativa à reforma liberal no campo da saúde: a reforma sanitária. O então recém-criado Sistema Único de Saúde (SUS) foi marcado nos anos 1990 por avanços político-institucionais e pela expansão da rede assistencial 4 . Foi nesse contexto que surgiram as OS, imediatamente alvos de oposição por movimentos sociais e no plano parlamentar. No meio jurídico administrativista, causaram polêmica o caráter inédito do papel desempenhado pelo setor privado e, sobretudo, a discricionariedade na escolha das entidades 5 . Todos esses fatores contribuíram para a Ação Direta de Inconstitucionalidade (ADI) no 1.923, impetrada contra a Lei Federal em 1998. A ADI, cujo julgamento ainda não foi concluído, gerou uma situação de instabilidade jurídica que, embora não tenha inibido a promulgação de leis subnacionais, permanece até hoje.

Convém situar as OS em relação a outras formas de participação do privado na saúde. Para tanto, recorre-se à tipologia de Maarse, segundo o qual se observam quatro formas de privatização no setor: da gestão, do financiamento, da provisão e do investimento ${ }^{6}$. Nesse sentido, se a privatização da gestão representada pelas OS pouco avançou nas duas primeiras décadas do SUS, o mesmo não se pode dizer de outros dois potentes processos não relacionados à reforma liberal de 1995, mas igualmente incentivados por políticas públicas. O primeiro foi a privatização do financiamento, ou seja, o aumento do gasto privado, que no Brasil está relacionado ao crescimento da saúde suplementar. A indução estatal, nesse caso, é exemplificada pelas políticas de estímulo à 
demanda, como a dedução fiscal dos gastos do consumidor de planos de saúde. Essas políticas favoreceram a expansão do mercado e geraram uma situação iníqua em que o usuário do sistema privado se beneficia de mais recursos do governo do que o usuário exclusivo do SUS 7. O segundo processo foi a privatização da provisão, que se refere à contratação, pelo poder público, de estabelecimentos privados para prestação de serviços para o SUS. Esse modelo, predominante antes de 1988, teve sua reprodução assegurada pelo marco legal do SUS - que caracterizou a função complementar do setor privado, com preferência para o setor não lucrativo 8 - e por medidas posteriores de incentivo ao setor privado contratado, que tem sido objeto de fraco controle 9 .

Tampouco se pode afirmar que alguma proposta alternativa às OS, para a questão administrativa, tenha se tornado dominante. A expansão e a municipalização da rede assistencial e a limitação dos gastos com funcionários públicos foram alguns dos fatores que contribuíram para uma situação de crise jurídico-administrativa caracterizada por precarização do trabalho, déficit de prestação de contas e baixa eficiência. $\mathrm{Na}$ ausência de uma reestruturação administrativa nacional, diferentes mecanismos vêm sendo testados. Têm ganhando popularidade e legitimidade a aplicação em estruturas públicas de estratégias gerenciais oriundas do setor privado. Nesses casos, mantém-se públicos financiamento, provisão, investimento e gestão, sendo introduzidos mecanismos como flexibilidade e autonomia administrativas e incentivos financeiros ao desempenho 10. Esse é o caso das Fundações Estatais de Direito Privado, dos contratos de gestão entre órgãos da administração pública 11, da Empresa Brasileira de Serviços Hospitalares, dos Contratos Organizativos de Ação Pública de Saúde 12 e dos termos de compromisso com unidades da administração direta no Estado de São Paulo, Brasil 13,14.

É nesse contexto de proliferação de reformas administrativas ad hoc que, no fim dos anos 2000, as OS ressurgem. Em 2006, o Município de São Paulo promulgou sua lei de OS e, três anos depois, já respondia por sete das 15 OS contratadas na esfera municipal em todo o país ${ }^{3}$. Em 2009, uma inflexão da lei estadual paulista ampliou significativamente o escopo do modelo e a cidade do Rio de Janeiro, Brasil, aprovou sua própria lei. Em 2011, foi a vez do Estado do Rio de Janeiro. Para além da insolvência da crise administrativa, explica esse recrudescimento a fadiga da crítica jurídica e da resistência política. Uma década depois, o julgamento da ADI no 1.923 ainda não foi concluído (o processo está há três anos sendo analisado por um dos ministros), a crítica na doutrina jurídica arrefeceu e as novas leis passam sem os calorosos debates dos anos 1990.

Fatores históricos ajudam a entender por que o Município de São Paulo foi um foco de reemergência das OS. A principal cidade do país já havia recorrido a parcerias com o setor privado em 1995, com o Plano de Assistência à Saúde, polêmico projeto que durou poucos anos 15. Além disso, a cidade inevitavelmente esteve sob influência da pioneira e importante experiência com o modelo no nível estadual, que data de 1998. A intensidade do processo na capital paulista, sua especificidade legal e a importância da cidade justificam seu estudo. Ressalte-se ainda a carência de pesquisas no tema em geral e em alguns aspectos em particular, como o controle público. A maioria dos estudos sobre OS estaduais paulistas versa sobre métodos organizacionais, desempenho e gestão financeira 13,14,16.

Este artigo, por sua vez, foca na regulação do governo municipal de São Paulo sobre as OS, e tem dois objetivos: caracterizar a privatização da gestão dos estabelecimentos da Secretaria Municipal de Saúde (SMS) e avaliar o papel regulatório da administração municipal sobre as entidades. Para a caracterização, procurou-se entender a importância relativa do modelo dentro da SMS, sua especificidade em relação a outras cidades e as características das entidades contratadas. Para a análise da regulação, procurou-se levantar e compreender os mecanismos regulatórios criados, o percurso de sua criação, a participação dos mecanismos preexistentes e a operação desta regulação.

Para responder a essas questões, foram definidos quatro eixos de análise. Primeiro, a magnitude do modelo, expressa pela sua participação na rede de estabelecimentos da SMS e por sua evolução no orçamento e na composição da força de trabalho da pasta. $\mathrm{O}$ segundo eixo foi o marco legal das OS em uma perspectiva evolutiva. O terceiro, a caracterização das entidades contratadas. E o quarto, o levantamento dos mecanismos regulatórios específicos e gerais e a análise de seu funcionamento.

\section{Metodologia}

Trata-se de um estudo descritivo baseado em fontes documentais, com o apoio em revisão bibliográfica. Os seguintes dados e fontes foram utilizados:

- Legislação disponível na base eletrônica do Legislativo municipal e estadual.

- Dados primários sobre estabelecimentos sob convênio e contratos de gestão em 2010, obtidos mediante solicitação à SMS 17,18. 
- Tabela de estabelecimentos de saúde em 2010; diapositivos de prestações de contas da SMS apresentadas em audiências públicas (Secretaria Municipal de Saúde de São Paulo. Prestação de contas. http://www.prefeitura.sp.gov.br/ cidade/secretarias/saude/prestacao_de_contas/ index.php?p=6163, acessado em 13/Dez/2013); e instrumento normativo de convênios 19 (todos disponíveis no site da SMS).

- Dados orçamentários e sobre regulação obtidos a partir dos Relatórios de Fiscalização do Tribunal de Contas do Município (TCM) [2010 e 2011 disponíveis no site (Tribunal de Contas do Município de São Paulo. Relatórios http://www. tcm.sp.gov.br/relatorios/capa_relatorio.htm, acessado em 02/Jun/2014); 2007 a 2009 obtidos mediante solicitação; 2012 obtidos mediante solicitação somente os dados orçamentários].

- Sites das entidades privadas contratadas.

- Relatório da Subcomissão de OS da Câmara Municipal 20.

Logo no início da pesquisa, constatou-se que a SMS privatizou a gestão de seus estabelecimentos não só por meio de contratos de gestão, mas também por convênios, os quais foram incluídos no estudo, como será explicado na próxima seção.

Para a descrição da evolução orçamentária, procedeu-se a uma composição de dados de duas fontes. A escolha pelo novo modelo não foi imediatamente seguida por uma reorganização contábil e, portanto, os descritivos orçamentários do TCM só passaram a explicitar os gastos com entidades privadas a partir de 2010. Para os anos anteriores, recorreu-se às prestações de contas da SMS.

Na análise do marco legal, comparou-se primeiro a lei municipal de São Paulo, de 2006, com a do Estado de São Paulo e com a federal, ambas de 1998. Como ficou claro que o texto da municipal se baseou no da estadual, esta foi incluída no estudo. Dois aspectos foram privilegiados com o fim de caracterizar a especificidade da lei: escopo (ou seja, os setores escolhidos para sua aplicação) e aparato regulatório. Optou-se por uma perspectiva evolutiva, comparando-se projeto, lei aprovada e modificações posteriores, a fim de evidenciar as negociações políticas que influenciaram a institucionalização do modelo.

$\mathrm{O}$ delineamento do perfil das entidades privadas se deu por meio de dados da SMS e de pesquisa no site de cada uma delas. Com base na pesquisa do MPOG ${ }^{3}$ e em outra do Instituto Brasileiro de Geografia e Estatística (IBGE) sobre o terceiro setor 21 , foram privilegiadas as seguintes informações: natureza jurídica, natureza do instituidor, finalidade original, público-alvo original e forma de disponibilização dos servi- ços originais (se por venda ou gratuitamente). A partir disso, foi proposta uma classificação das entidades em sete categorias. Pesquisou-se a presença das entidades na lista de OS vinculadas ao estado e em um ranking nacional de empresas do setor saúde.

A pesquisa se baseia em uma perspectiva administrativista e política. Parte-se do pressuposto de que políticas públicas são, em grande parte, resultado de negociações entre setores da sociedade civil que se fazem representar junto ao Estado, influenciando agentes governamentais sobretudo quando tais políticas envolvem o setor privado. Valoriza-se, portanto, o papel dos atores, sem deixar de reconhecer outros fatores como a conformação das instituições existentes, o contexto internacional ou os processos eleitorais. A flutuação no mix público-privado na saúde brasileira, especialmente no que se refere à indução pública do mercado, tem sido um exemplo dessa articulação de interesses 7. O caso das OS coloca um desafio adicional no estudo da relação público-privada, visto que se trata de uma fração do setor privado polimórfica, sobre a qual a compreensão ainda é incipiente.

Nesse sentido, para analisar a regulação, parte-se de uma problematização do conceito, opondo duas dimensões do termo: a técnica, ou seja, como estabelecimento e operação de um conjunto de normas baseadas em conhecimento técnico e científico; e a dimensão política, como negociação, resolução de conflitos e equilíbrio de poderes 22 .

\section{Resultados}

\section{Contratos de gestão vs convênios}

O primeiro resultado desta pesquisa foi que grande parte dos ajustes regulando a privatização da gestão não eram contratos de gestão, mas convênios. Porém, esse uso do convênio vai ao encontro da sua definição na doutrina jurídica e da sua utilização tradicional na administração pública, a saber: um instrumento de fomento a uma entidade privada que realiza atividade de interesse público com sua própria estrutura e pessoal. Esses convênios reconfigurados se igualam aos contratos de gestão das OS em seu aspecto fundamental e inovador, a delegação da gestão de equipamento público ao setor privado. Portanto, foram incluídos na pesquisa. Como as entidades não podem, tecnicamente, ser chamadas de OS quando gerindo por meio de convênio, foi proposto o termo "entidades conveniadas OS símiles". 
A explicação histórica para a persistência do convênio é que ele foi a forma que a prefeitura encontrou para efetivar a privatização da gestão antes da lei de OS. Em 2005, o então prefeito José Serra afirmou que a lei de OS seria importante para regularizar e "dar mais legalidade ao processo" 23. O que era provisório, no entanto, se perenizou. Segundo Pahim 16, que analisou as OS do Estado de São Paulo, o convênio foi utilizado ainda com entidades que não puderam ser qualificadas como OS por falta de algum requisito legal - como a presença de membros da comunidade no Conselho de Administração -, o que poderia exigir processos morosos de mudanças no estatuto. A Portaria no 2.373 da SMS, de dezembro de 2013 , esclareceu que se pretende a conversão dos convênios em contratos de gestão, mas determinou a prorrogação dos convênios, expirados naquele mês, enquanto não se procedesse a um chamamento público para as OS.

\section{Magnitude da privatização da gestão}

Como mostra a Figura 1, em 2010, 61\% dos 936 estabelecimentos da rede municipal de saúde estavam sob gestão privada, com predomínio de entidades conveniadas OS símiles (36\% contra $25 \%$ sob gestão de OS). Desagregando a rede por setores, tem a gestão privatizada $72 \%$ da atenção básica, 59\% dos hospitais, $40 \%$ dos ambulatórios especializados e $1 \%$ do restante da rede. Outro aspecto relevante é a mudança do perfil do vínculo do trabalhador. Entre 2004 e 2012, o aumento do número de empregados vinculados à SMS foi de $68 \%$. Porém, enquanto o número de servidores ou empregados das autarquias se manteve estável, o número de contratados por OS ou OS símiles aumentou em $375 \%$, passando a responder por $48 \%$ do total.

Em relação à participação no orçamento, foram pesquisados os repasses da SMS para as entidades parceiras desde 2007, ano dos primeiros contratos de gestão. Os relatórios do TCM apresentam as despesas separadas em diferentes rubricas com códigos numéricos criados pela SMS. No entanto, as rubricas utilizadas até 2009 não permitiam uma visualização clara do quanto se repassava às parceiras. Para os anos anteriores a 2010, portanto, foram usadas as prestações de contas da própria SMS, de menor rigor contábil, como se pode aferir pelo fato de que as cifras são dadas em valores empenhados (ou seja, reservados para pagamento), que são superestimados em relação aos preferíveis valores liquidados (ou seja, comprometidos com pagamento).

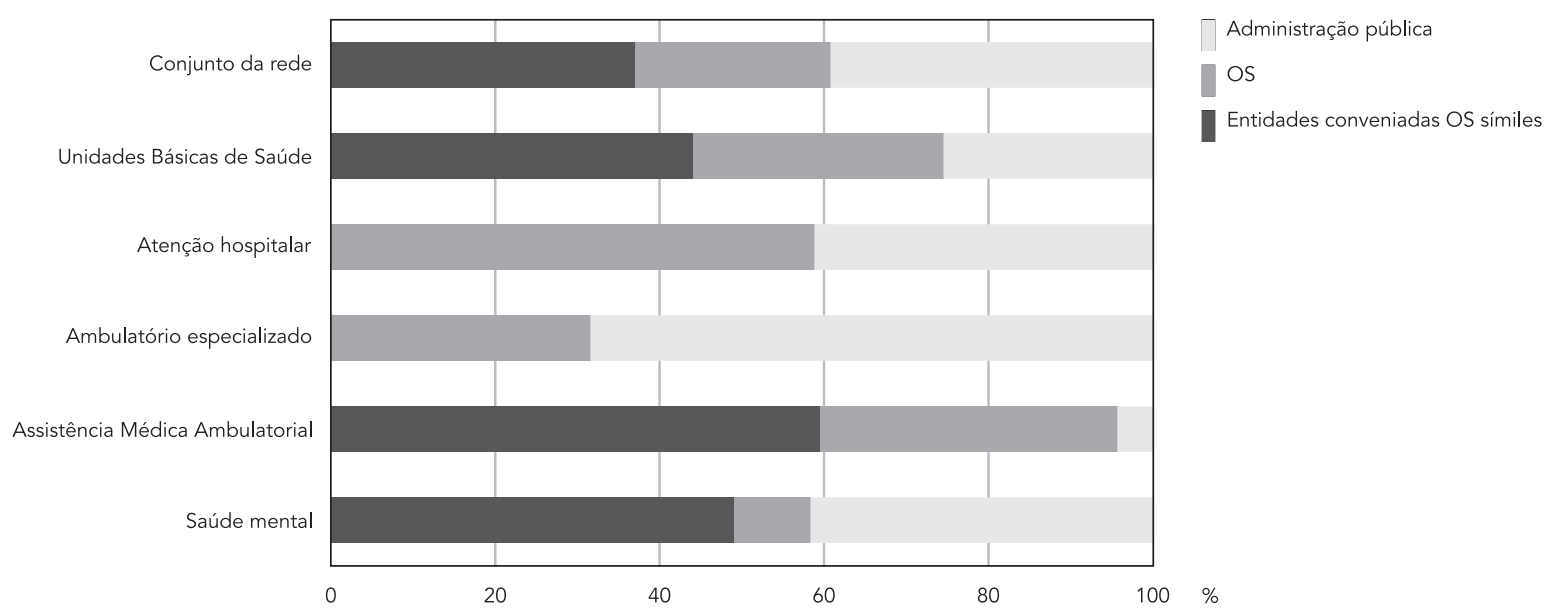

\footnotetext{
* Como os dados do total de estabelecimentos são alguns meses mais recentes que o de convênios e contratos, pode haver superestimação das unidades sob administração pública, calculadas por subtração, especialmente para a Assistência Médica Ambulatorial, que estava em expansão à época. Fontes: Secretaria Municipal de Saúde de São Paulo 17,18.
} 
A Tabela 1 relaciona os gastos com diferentes atividades da SMS de acordo com a fonte. Observam-se, a partir de 2010, novas rubricas codificadas por atividade $(4.123,4.124,4.125,4.126)$, criadas pela SMS após críticas do TCM. Um padrão, no entanto, se manteve: os gastos com OS estão explícitos sob uma descrição ou rubrica de nome “OS”, enquanto os gastos com OS símiles estão desagregados por programa, o que compromete sua transparência. Isso ainda induz a uma subestimação da despesa com cada programa, já que a descrição ou rubrica com o nome do programa se refere, na verdade, somente às unidades sob convênio.

No entanto, em 2010 a SMS avançou em transparência ao corrigir outro tipo de classificação de despesa, as rubricas codificadas por elemento. Antes, eram reunidos no mesmo elemento repasses para OS e pagamentos a serviços de limpeza terceirizados, por exemplo. Após crítica do TCM, a SMS criou o elemento 335039 para as transferências a pessoas privadas sem fins lucrativos. Isso agregou as despesas com OS e OS símiles, permitindo emergir a despesa total da prefeitura com a privatização da gestão.

A Figura 2, apesar da inevitável imprecisão nos dados de 2007 a 2009 pelas razões citadas, evidencia a crescente participação da gestão privada no orçamento da saúde, atingindo $41 \%$ (23,7\% para OS e 20,3\% para OS símiles) em 2012. É digno de nota que as OS só ultrapassaram as OS símiles em termos de recursos em 2010.

\section{Marco legal}

Em 1998, foi aprovada a lei de OS do Estado de São Paulo, a Lei Complementar (LC) no 846, após intensa resistência na Assembleia Legislativa e por setores da sociedade civil, que criticaram o fraco controle sobre as entidades 24 . Algumas restrições foram impostas ao projeto original: a exclusividade de atendimento ao SUS (já que o projeto deixava este aspecto em aberto); a limitação do modelo às unidades novas; e a inclusão de Comissão de Avaliação com membros do Executivo, Legislativo e Conselho Estadual de Saúde. Porém, nos anos seguintes, algumas dessas restrições caíram. Em 2009, a LC no 1.095 agregou às áreas originais - saúde e cultura - as áreas de esporte e atendimento às pessoas com deficiência. Mas a grande ampliação do escopo foi a aplicação da lei também aos estabelecimentos de saúde antigos. Nesse mesmo ano, a Assembleia votou a reserva de $25 \%$ dos leitos dos hospitais geridos por OS para pacientes de planos de saúde e particulares, e aprovou; o Executivo, porém, vetou. Em 2010, o tópico foi novamente encaminhado pelo Executivo e enfim aprovado como a $L C$ no 1.131 .
Entidades civis entraram com ação no Ministério Público Estadual, que emitiu liminar suspendendo a reserva de leitos para o mercado. O Executivo entrou com recurso, que foi julgado improcedente em 2012. A LC no 1.243 de 2014 consolidou essa decisão, alterando a lei de OS de forma a excluir o atendimento ao mercado. No entanto, ampliou novamente o escopo do modelo, que agora passa a incluir proteção da criança e do adolescente, meio ambiente e "promoção de investimentos, de competitividade e de desenvolvimento".

A capital aprovou sua lei de OS, a Lei Municipal no 14.132, somente em 2006. Uma das diferenças trazidas pela lei em relação ao seu projeto foi a restrição do modelo de OS à saúde. Desde o início as OS se aplicaram tanto a unidades novas como antigas, e foi previsto chamamento público e seleção para sua contratação. Foi instituída uma Comissão de Avaliação, com dois membros indicados pela Câmara, quatro pelo Executivo e dois escolhidos entre membros do Conselho Municipal de Saúde ou de Conselhos Gestores de unidades de saúde. Sua função era avaliar contratos e acompanhar sua execução. Em 2008, a Lei Municipal no 14.664 expandiu a área de atuação das OS, agregando esporte e lazer. Além disso, foi modificado o controle: a Comissão de Avaliação se restringiria à análise de contratos antes de sua assinatura, e uma nova Comissão de Acompanhamento e Fiscalização (CAF) - composta por dois membros da sociedade civil (que não foram definidos como sendo das instâncias de controle social) e três do Executivo - acompanharia o contrato. $\mathrm{O}$ texto é ambíguo se haveria uma CAF para cada contrato ou uma por secretaria envolvida. Em 2011, o Decreto no 52.858 incluiu a área da cultura.

As entidades conveniadas OS símiles não possuem marco legal específico, sendo sua regulação normatizada por um instrumento normativo elaborado pela SMS.

\section{Perfil das entidades privadas}

A Tabela 2 relaciona as vinte entidades que em 2010 gerenciavam serviços de saúde da Prefeitura de São Paulo; apresenta o número de estabelecimentos geridos por cada uma segundo o tipo de ajuste; aponta quais também têm parceria na esfera estadual 16; e, quando cabível, mostra a posição das entidades no ranking nacional das maiores empresas do setor 25 .

Verificou-se que quatro entidades estabeleciam parcerias exclusivamente por contratos de gestão; nove somente por meio de convênios; e sete pelos dois instrumentos. O grupo, que reflete a diversidade e a dificuldade de classificação própria ao terceiro setor, foi dividido em sete 
Valores destinados pela Secretaria Municipal de Saúde de São Paulo a Organizações Sociais (OS) e entidades conveniadas OS símiles de 2007 a 2012, em Reais.

\begin{tabular}{|c|c|c|c|c|c|c|c|}
\hline Descrição/Rubrica & Fonte & 2007 & 2008 & 2009 & 2010 & 2011 & 2012 \\
\hline \multicolumn{8}{|l|}{ OS } \\
\hline Gastos com OS & SMS & 76.038 .854 & 308.976 .942 & 662.903 .367 & & & \\
\hline $\begin{array}{l}\text { Atividade } 4125 \text { (OS } \\
\text { ambulatorial) }\end{array}$ & TCM & & & & 605.788 .017 & 699.147 .065 & 728.873 .840 \\
\hline $\begin{array}{l}\text { Atividade } 4126 \text { (OS } \\
\text { hospitalar) }\end{array}$ & $\mathrm{TCM}$ & & & & 377.811 .684 & 480.227 .546 & 501.890 .410 \\
\hline Total OS & & 76.038 .854 & 308.976 .942 & 662.903 .367 & 983.599 .700 & 1.179 .374 .611 & 1.230 .764 .250 \\
\hline \multicolumn{8}{|l|}{$\begin{array}{l}\text { Entidades conveniadas OS } \\
\text { símiles }\end{array}$} \\
\hline Atividade 4111 (ESF) & TCM & 331.303 .822 & 350.739 .274 & 460.204 .429 & 470.295 .708 & 531.180 .762 & 558.205 .212 \\
\hline $\begin{array}{l}\text { Gastos com Assistência } \\
\text { Médica Ambulatorial }\end{array}$ & SMS & 66.802 .268 & 253.686 .332 & 291.465 .882 & & & \\
\hline $\begin{array}{l}\text { Atividade } 4123 \\
\text { (Assistência Médica } \\
\text { Ambulatorial) }\end{array}$ & $\mathrm{TCM}$ & & & & 369.930 .034 & 369.580 .035 & 394.971 .910 \\
\hline $\begin{array}{l}\text { Atividade } 4124 \text { (saúde } \\
\text { mental)* }\end{array}$ & TCM & & & & 49.409 .114 & 73.075 .125 & 102.074 .164 \\
\hline Total OS símiles & & 398.106 .090 & 604.425 .606 & 751.670 .311 & 889.634 .856 & 1.000 .835 .922 & 1.055.251.287 \\
\hline $\begin{array}{l}\text { OS + entidades } \\
\text { conveniadas OS símiles }\end{array}$ & & & & & & & \\
\hline Por soma ** & & 474.144 .944 & 913.402 .548 & 1.414 .573 .678 & 1.873 .234 .556 & 2.180 .210 .533 & 2.286 .015 .537 \\
\hline 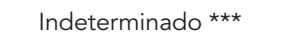 & & & & & 8.672 .225 & 39.451 .010 & 8.254 .260 \\
\hline Elemento 335039 \# & $\mathrm{TCM}$ & & & & 1.881 .906 .781 & 2.219 .661 .543 & 2.294 .269 .797 \\
\hline
\end{tabular}

ESF: Estratégia Saúde da Família; SMS: Secretaria Municipal de Saúde; TCM: Tribunal de Contas do Município.

* Antes de 2010, não havia informação sobre o gasto com saúde mental nas prestações de contas da SMS;

** Soma dos totais de OS e OS símiles obtidos por somatório dos valores das rubricas de atividades do TCM ou descrições da SMS. É a única forma de calcular o total dos repasses até 2009 .

*** Esse valor residual se refere à diferença entre o total de OS e OS símiles segundo o elemento de despesa 335039 e o total calculado por soma; não se pode determinar a qual dos dois tipos de parceria esse valor foi repassado;

\# A rubrica elemento de despesa 335039 (outros serviços de terceiros - pessoa jurídica), criada em 2010, se refere aos repasses a pessoas privadas sem fins lucrativos e reúne os repasses tanto às OS quanto a entidades conveniadas OS símiles.

Fontes: quando existentes, usaram-se dados do TCM, referentes a valores liquidados (Tribunal de Contas do Município de São Paulo. Relatórios http://www.tcm.sp.gov.br/relatorios/capa_relatorio.htm, acessado em 02/Jun/2014). Na falta destes, usaram-se dados da SMS, referentes a valores empenhados. (Secretaria Municipal de Saúde de São Paulo. Prestação de contas. http://www.prefeitura.sp.gov.br/cidade/secretarias/saude/prestacao_de_ contas/index.php?p=6163, acessado em 13/Dez/2013). Elaboração própria.

categorias. O primeiro grupo abrange as tradicionais instituições filantrópicas religiosas, que prestam assistência em saúde tanto no mercado quanto no SUS, pelo que recebem fomento estatal. O segundo reúne os dois mais destacados hospitais privados do país, que, embora voltados ao mercado, mantêm a qualificação de filantrópicos em troca de serviços ao poder público. $\mathrm{O}$ terceiro é um hospital privado filantrópico ligado a uma universidade pública, de forte atuação no setor público no ensino e na assistência, mas que também atende ao mercado.
O quarto grupo se aproxima do impreciso conceito de organização não governamental (ONG). São instituições originadas no seio de uma comunidade - seja por auto-organização, seja por iniciativa de particulares externos - com a finalidade de prestação de serviços gratuitos. $\mathrm{O}$ quinto grupo é composto por entidades de apoio administrativo, geralmente criadas por dirigentes de instituições universitárias ou hospitalares com o objetivo de flexibilizar sua gestão. O sexto é formado por entidades criadas por particulares e que oferecem assessoria em gestão para 
Figura 2

Evolução da participação das Organizações Sociais (OS) e das entidades conveniadas OS símiles no orçamento da Secretaria Municipal de Saúde de São Paulo de 2007 a 2012, em porcentual.
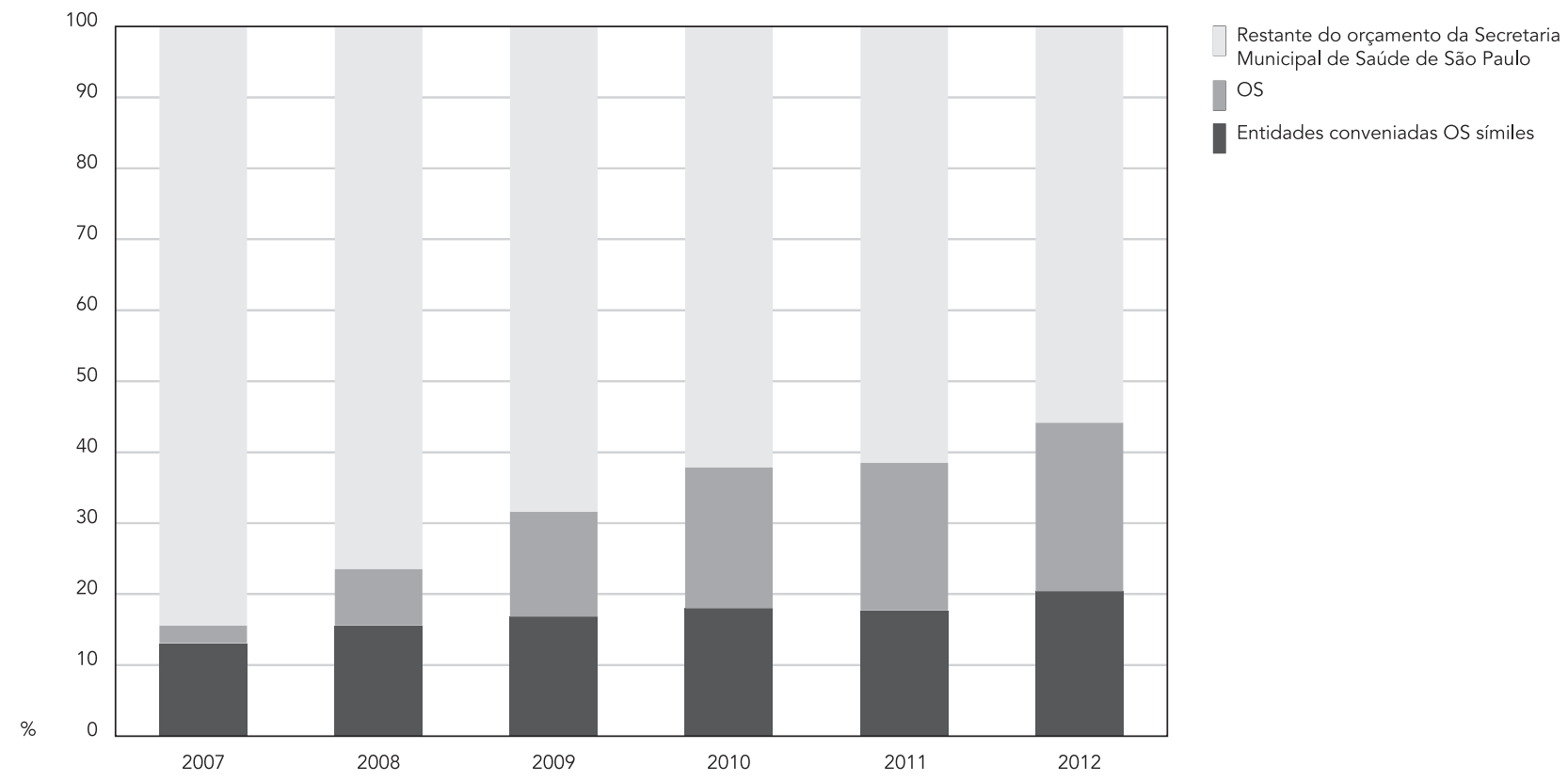

Fontes: Secretaria Municipal de Saúde de São Paulo. Prestação de contas. http://www.prefeitura.sp.gov.br/cidade/secretarias/saude/prestacao_de_contas/ index.php?p=6163 (acessado em 13/Dez/2013); Tribunal de Contas do Município de São Paulo. Relatórios http://www.tcm.sp.gov.br/relatorios/capa_relatorio. htm (acessado em 02/Jun/2014).

instituições de saúde. Por fim, o sétimo grupo é o Serviço Social Autônomo do setor da construção civil.

Quase todas as entidades já eram fomentadas pelo Estado. Algumas nunca haviam se envolvido em prestação direta de assistência à saúde. Outras já estavam implicadas na gestão de serviços próprios, que em alguns casos faziam parte do SUS por meio de convênios tradicionais de fomento.

Verificou-se que, de um lado, há pequenas instituições de âmbito local gerindo somente um ou dois estabelecimentos. De outro, grandes conglomerados responsáveis por mais de cem serviços. Chama a atenção o fato de que cinco dessas entidades incluem-se entre as dez maiores empresas do país no setor de serviços médicos (note-se que o ranking não diferencia entidades lucrativas de não lucrativas, chamando todas de empresas). A parceria com o poder público contribuiu para o crescimento dessas entidades, que não mantêm vínculos somente com a prefeitura paulistana. A Associação Paulista para o Desen- volvimento da Medicina (SPDM), por exemplo, a segunda do ranking, tem vínculos com vários outros municípios paulistas, com o Estado de São Paulo, com o Município do Rio de Janeiro e com Santa Catarina. Outras cinco entidades também possuem parcerias no nível estadual.

\section{Regulação}

Em relação ao aparato regulatório específico das OS, verificou-se que, além da Comissão de Avaliação e da CAF criadas por lei, foi instituído na SMS o Núcleo Técnico de Contratação de Serviços de Saúde (NTCSS), responsável por elaborar instrumentos de monitoramento e avaliar relatórios das entidades. As OS estão também sujeitas a mecanismos gerais representados pela Auditoria Geral, ligada à Secretaria de Finanças, que supervisiona quaisquer contratos, e pelo controle externo (ao Poder Executivo), exercido tanto pelo Judiciário quanto pelo Legislativo. Ambos os poderes têm sido atuantes no tema e constituem fontes detalhadas sobre o controle interno. 
Tabela 2

Entidades em parceria com a Secretaria Municipal de Saúde de São Paulo para gestão de serviços de saúde, por contrato de gestão ou convênio, em 2010 número de serviços geridos por tipo de ajuste e características.

\begin{tabular}{|c|c|c|c|c|c|c|c|c|c|c|c|c|c|c|c|c|c|c|c|c|}
\hline Entidades & 1 & 2 & 3 & 4 & 5 & 6 & 7 & 8 * & 9 & 10 & $11 * \star$ & 12 & 13 & 14 & 15 & 16 & 17 & 18 & 19 & $20 \#$ \\
\hline \multicolumn{21}{|l|}{ Número de serviços } \\
\hline Por convênio & 2 & 14 & - & 1 & 121 & 9 & 1 & 2 & 7 & 41 & 7 & - & 12 & 5 & 6 & - & 17 & - & 3 & 96 \\
\hline $\begin{array}{l}\text { Por contrato de } \\
\text { gestão }\end{array}$ & - & - & 42 & - & - & - & - & 27 & - & 57 & 9 & 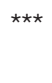 & - & 1 & 15 & 1 & - & 1 & 18 & 53 \\
\hline Total & 2 & 14 & 41 & 1 & 121 & 9 & 1 & 29 & 7 & 96 & 16 & - & 12 & 6 & 21 & 1 & 17 & 1 & 21 & 148 \\
\hline \multicolumn{21}{|l|}{ Classificação } \\
\hline Filantropia religiosa & & & $x$ & & & $x$ & & & $x$ & $x$ & & & $x$ & & $x$ & & & $x$ & & \\
\hline $\begin{array}{l}\text { Hospital privado } \\
\text { (mercado) }\end{array}$ & & & & & & & & & & & & & & $x$ & & & $x$ & & & \\
\hline $\begin{array}{l}\text { Hospital privado } \\
\text { (universidade) }\end{array}$ & & & & & & & & & & & & $x$ & & & & & & & & $x$ \\
\hline ONG & $x$ & $x$ & & & & & $x$ & & & & & & & & & & & & & \\
\hline Apoio administrativo & & & & & & & & $x$ & & & $x$ & & & & & & & & & \\
\hline Assessoria de gestão & & & & $x$ & $x$ & & & & & & & & & & & & & & & \\
\hline $\begin{array}{l}\text { Serviço social } \\
\text { autônomo }\end{array}$ & & & & & & & & & & & & & & & & & & & $x$ & \\
\hline Outros & & & & & & & & & & & & & & & & & & & & \\
\hline $\begin{array}{l}\text { Contrato de gestão } \\
\text { com a SES }\end{array}$ & & & $x$ & & & & & & & $x$ & $x$ & & & & $x$ & & & & $x$ & $x$ \\
\hline Posição no ranking \#\# & - & - & 6 & - & - & - & - & - & - & 10 & 19 & - & - & - & 8 & - & 4 & - & - & 2 \\
\hline
\end{tabular}

SES: Secretaria de Estado de Saúde; ONG: Organização Não-governamental.

1. Associação Comunitária e Beneficente Padre José Augusto Machado Moreira; 2. Associação Comunitária Monte Azul; 3. Associação Congregação de Santa Catarina; 4. Associação Pró-Saúde Mental; 5. Associação Saúde da Família; 6. Centro Social Nossa Senhora do Bom Parto; 7. Casa de Isabel; 8. Centro de Estudos e Pesquisas Dr. João Amorim; 9. Congregação das Irmãs Hospitaleiras do Sagrado Coração de Jesus; 10. Casa de Saúde Santa Marcelina; 11. Fundação Faculdade de Medicina; 12. Fundação Instituto de Pesquisa e Estudo de Diagnóstico por Imagem; 13. Instituto Adventista de Ensino/Centro Universitário Adventista de São Paulo); 14. Instituto de Responsabilidade Social Sírio-Libanês; 15. Irmandade da Santa Casa de Misericórdia de São Paulo; 16. Instituto SAS; 17. Sociedade Beneficente Israelita Brasileira Hospital Albert Einstein; 18. Santa Casa de Misericórdia de Santo Amaro; 19. Serviço Social da Construção Civil do Estado de São Paulo; 20. Associação Paulista para o Desenvolvimento da Medicina.

* A Cejam foi criada como entidade de apoio administrativo do Hospital Pérola Byngton, que é privado;

** A FFM foi criada como entidade de apoio administrativo para o Hospital das Clínicas da Faculdade de Medicina da Universidade de São Paulo. No ranking da Valor 1000, aparece sob sua razão social Icesp (Instituto de Câncer do Estado de São Paulo), hospital sob sua administração 25;

*** A Fidi, ligada à SPDM/Hospital São Paulo, não administra nenhum serviço, mas o setor de exames de imagem de diversos serviços de saúde; \# O Hospital São Paulo e a Escola Paulista de Medicina eram uma mesma pessoa privada. Quando a escola foi federalizada, o hospital não o foi. Criou-se, portanto, a SPDM como pessoa jurídica para o Hospital São Paulo (nome que é usado como razão social), que hoje em dia tem atuação tanto privada (atendimento no mercado) quanto pública (atendimento no SUS e como hospital de ensino da Universidade Federal de São Paulo);

\#\# Ranking nacional de empresas do setor de serviços médicos em 2012, segundo receita líquida.

Fontes: Sites das entidades, Secretaria Municipal de Saúde de São Paulo 17,18, Revista Valor Econômico 25, Pahim 16. Elaboração própria.

O Poder Judiciário tem se feito presente por meio do TCM, que desde 2007 tem dedicado atenção especial às OS. Foram identificadas diversas irregularidades: a prefeitura não respeitou a lei que exigia a constituição das CAF, instituindo a primeira somente no fim de 2010; não cumprimento das obrigações por parte da CAF; não cumprimento de metas; não execução de todo o dinheiro repassado; escassez de funcionários no NTCSS e falta de informatização; aprovação pelo NTCSS de prestações de contas com erros; falhas na elaboração de indicadores de desempenho; desrespeito aos regulamentos de compras; atrasos nos repasses dos recursos por parte da SMS.

As reiteradas recomendações do TCM, em muito ignoradas pela SMS, levaram a Câmara Municipal a instaurar a Subcomissão das OS, comissão de investigação com o objetivo de avaliar a efetividade regulatória do Executivo e cujos trabalhos foram conduzidos de junho a setembro de 2011. Entre as conclusões da Subcomissão estavam: o despreparo da SMS em controlar os 
vultuosos contratos; o fato de que continuava havendo somente uma CAF em vez de uma para cada contrato de gestão; a existência de contratos que não haviam sido avaliados pela Comissão de Avaliação; e a omissão da Auditoria Geral, que nunca havia auditado nenhum dos contratos de gestão.

Sobre a possibilidade de fiscalização pela sociedade, alguns aspectos se destacam: foi prejudicada pelo atraso na constituição da CAF; a disponibilização dos contratos de gestão na internet constitui um avanço em transparência; as audiências públicas de prestações de contas da SMS conferiram especial atenção às OS, que ocuparam 47, 17, 17, 18 e 7 páginas, respectivamente, entre os anos de 2008 e 2012. Ressalte-se, contudo, que foram apresentados somente dados sobre orçamento e cobertura dos serviços, tendo sido excluídos os indicadores de resultados, cumprimento de metas ou gestão financeira.

$\mathrm{O}$ aparato regulatório direcionado às entidades conveniadas OS símiles está descrito em um documento chamado "Instrumento Normativo", lançado pela SMS em 2008. Baseia-se em controle contábil e de resultados, aferidos com base em indicadores de gestão de material, de recursos humanos, epidemiológicos e operacionais. Para a análise dos indicadores, foram criadas Comissões de Acompanhamento formadas por gestores da SMS e submetidas à Coordenadoria de Atenção Básica. Os convênios não são fiscalizados pelo NTCSS.

Em relação ao controle externo, verificou-se que o TCM abordou os convênios nos relatórios de 2007 e 2008, criticando a debilidade da fiscalização e a subutilização de recursos repassados. O tópico, porém, está ausente nos relatórios entre 2009 e 2011. O relatório da Subcomissão das OS da Câmara também ignorou os convênios. Vale destacar que, à época, provavelmente ainda não fora publicado o relatório do TCM em que as despesas com OS símiles ganharam visibilidade em razão da reorganização da descrição orçamentária.

O papel fiscalizador da sociedade civil é limitado nos convênios: não está prevista a sua participação nas Comissões de Acompanhamento; os ajustes não estão disponíveis na internet nem foram fornecidos quando solicitados para esta pesquisa; e, nas prestações de contas da SMS, aos convênios é destinada somente uma página a cada ano, limitando-se a informação ao total repassado por entidade.

\section{Discussão}

Os achados desta pesquisa podem ser resumidos em cinco pontos. Primeiro, a intensidade do processo, possibilitada pelo amplo escopo da lei municipal. Segundo, a volubilidade do marco legal. Isso é visível, sobretudo, na evolução da lei estadual, que foi modificada segundo as diferentes correlações de forças ao longo dos sucessivos mandatos, com destaque para as reiteradas tentativas de abrir para o mercado hospitais estaduais de ponta (como o Instituto do Câncer e o Hospital de Transplantes), o que acabou sendo aprovado e só foi revertido após intervenção da sociedade civil e do Judiciário. O terceiro ponto é o gigantismo de algumas das entidades parceiras. O quarto é a desregulação das parcerias com as OS, que tiveram seu aparato regulatório sistematicamente negligenciado pela administração municipal. E o quinto é a desregulação ainda mais grave das entidades conveniadas OS símiles, de menor visibilidade política: padeceram durante anos de opacidade orçamentária; têm seu controle restrito a um setor da SMS; têm sido invisíveis à fiscalização do Judiciário e do Legislativo; e não foram convertidas para OS mesmo oito anos após a Lei no 14.132. Tais resultados levam à conclusão sobre a inadequação do papel regulatório que a prefeitura se propôs e suscitam questões sobre os condicionantes desta lacuna.

A originalidade das OS exigiu uma renovação do aparato fiscalizador, cuja materialização institucional pode ser dividida em três estágios. Primeiro, a formulação, seja da lei, pela Câmara, ou pela própria SMS em sua reorganização administrativa. Segundo, a operação dessas instâncias. Terceiro, a supervisão ou o controle externo que deve assegurar a satisfatoriedade dos estágios prévios. Regulação é, portanto, o resultado da interação dos três poderes, ainda que, em um sentido estrito, possa se referir à sua operação no interior do Executivo. Constituem vulnerabilidades no estágio da formulação a volubilidade da lei de OS e a inadequação do regulamento criado pela SMS para os convênios. A omissão da administração municipal é uma falha na operação. Finalmente, a refratariedade da SMS às recomendações do TCM, assim como o fato de este e a Câmara Municipal terem ignorado as OS símiles em suas críticas constituíram insuficiências na supervisão.

Quais são as razões para tal falha tantos anos após a lei de OS ter sido promulgada? Se priorizarmos a dimensão técnica da regulação, a resposta apontaria para o institucional ou gerencial. A lei de OS ainda não estaria suficientemente lapidada; o NTCSS foi mal projetado; dificuldades burocráticas dificultaram a constituição das CAF. 
Nesse sentido, o alcance de uma regulação ótima seria uma questão de tempo; de alterações na lei de OS; de desenvolvimento da expertise regulatória da prefeitura; de conversão dos convênios em contratos de gestão.

No entanto, a desregulação também deve ser entendida como resultado de uma negociação política entre diversas partes. As alterações no marco legal estadual que reverteram antigas restrições à atuação das OS, com destaque para a reserva de leitos públicos para a medicina privada, tornam evidente o alcance do interesse privado e o fato de que a discussão das OS vai além do técnico. Além disso, como visto, entre as entidades parceiras da prefeitura estão cinco das dez maiores empresas do Brasil no ramo de serviços médicos. Ou seja, mais do que um campo de desinteressada filantropia ou a representação de uma difusa e auto-organizada sociedade civil, o terceiro setor é um campo de fortíssima atividade econômica. Se não gera lucros diretamente, gera receita, superávit, expansão, concentração e poder - e, com isto, interesses particulares. Portanto, a fragilidade regulatória da administração municipal, em uma perspectiva política, pode também ser entendida como resultado de sua permeabilidade ao interesse privado em um contexto de oposição atenuada.

É com base na premissa do confronto de interesses que se estabelecem os controles nos contratos que o Estado estabelece com o mercado. O chamado terceiro setor, contudo, idealizado como "setor público não-estatal", tem merecido uma atitude indulgente. No entanto, valendo-se da experiência de São Paulo pode-se afirmar que a administração gerencial baseada no setor privado está longe de cumprir suas principais promessas: a eficiência - que por definição exige um controle financeiro estrito - e a blindagem contra o patrimonialismo.

A crescente penetração do terceiro setor no Estado justifica a condução de mais pesquisas neste campo, nas várias experiências com OS em curso. Além da regulação, outros assuntos interessam no tema das OS, como a influência de diferentes formas de privatização e do gerencialismo sobre acesso, equidade e natureza dos bens de saúde, ou a relação entre terceiro setor e mercado.

\section{Resumen}

El trabajo caracteriza y discute la privatización de la gestión del sistema municipal de salud de la ciudad de São Paulo, Brasil, desde una perspectiva administrativa y política. La metodología se basó en un análisis bibliográfico, legislativo y de documentos públicos. La investigación demostró que, aunque la ley de Organizaciones Sociales (OS) sea de 2006, la mitad de la gestión privada está todavía regulada por un instrumento legal provisional anterior, el convenio. En 2011, un 61\% de los servicios se encontraban gestionados por entidades privadas que, en 2012, recibieron un 44\% del presupuesto de salud. Entre las 20 entidades involucradas, existen 5 de los 10 mayores grupos privados de servicios médicos del país. Órganos fiscalizadores muestran fallos en el control de las OS, pero los convenios, cuyo control es más débil, han sido invisibles a ojos de estos órganos de fiscalización. Finalmente, cabe destacar que el marco legal es inestable. A partir de la experiencia de São Paulo, se discute el carácter técnico vs. político de la regulación en la gestión privada en el Sistema Único de Salud (SUS).

Gestión en Salud; Reforma de la Atención de Salud; Privatización 


\section{Colaboradores}

H. Contreiras participou do desenho da pesquisa, coleta e análise de dados e redação do artigo. G. C. Matta orientou a pesquisa, revisou criticamente o trabalho e aprovou a versão final.

\section{Agradecimentos}

Agradecemos à Coordenação de Pós-graduação da Escola Politécnica de Saúde Joaquim Venâncio, Fundação Oswaldo Cruz, e aos colegas de turma, que possibilitaram a realização desta pesquisa no âmbito do Mestrado Profissional em Educação Profissional em Saúde. Em especial, ao apoio de Virgínia Fontes.

\section{Referências}

1. Costa NR, Silva PLB, Ribeiro JM. A experiência internacional de reforma do setor saúde: inovações organizacionais e de financiamento. Rev Adm Pública 2000; 34:209-27.

2. Bustamante AV, Mendez CA. Health care privatization in Latin America: comparing divergent privatization approaches in Chile, Colombia, and Mexico. J Health Polit Policy Law 2014; 39:841-86.

3. Graef A, Salgado V. Relações de parceria entre o Poder Público e entes de cooperação e colaboração no Brasil. Brasília: Editora IABS; 2012.

4. Machado CV, Baptista TWF, Nogueira CO. Políticas de saúde no Brasil nos anos 2000: a agenda federal de prioridades. Cad Saúde Pública 2011; 27: 521-32.

5. Di Pietro MSZ. Parcerias na administração pública: concessão, permissão, franquia, terceirização, parceria público-privada e outras formas. 5a Ed. São Paulo: Editora Atlas; 2005.

6. Maarse H, Scatena JHG. The privatization of health care in Europe: an eight-country analysis. J Health Polit Policy Law 2006; 31:981-1014.

\section{Conflito de interesses}

H. Contreiras é funcionário de uma Organização Social, atuando como médico plantonista.
7. Bahia L. O sistema de saúde brasileiro entre normas e fatos: universalização mitigada e estratificação subsidiada. Ciênc Saúde Coletiva 2009; 14: 753-62.

8. Carvalho G. A saúde pública no Brasil. Estud Av 2013; 27:7-26.

9. Romano CMC. A relação público-privada no SUS um olhar sobre a assistência ambulatorial de média e alta complexidade na região de saúde da Baixada Cuiabana em Mato Grosso. Rev Adm Pública 2014; 48:439-58.

10. Araujo MAD. Responsabilização pelo controle de resultados no Sistema Único de Saúde no Brasil. Rev Panam Salud Pública 2010; 27:230-6.

11. Ditterich RG, Moysés ST, Moysés SJ. O uso de contratos de gestão e incentivos profissionais no setor público de saúde. Cad Saúde Pública 2012; 28: 615-27.

12. Lima SML, Rivera FU. A contratualização nos hospitais de ensino no Sistema Único de Saúde brasileiro. Ciênc Saúde Coletiva 2012; 17:2507-21. 
13. Barbosa NB, Elias PEM. As organizações sociais de saúde como forma de gestão público/privado. Ciênc Saúde Coletiva 2010; 15:2483-95.

14. Perdicaris PR. Contratualização de resultados e desempenho no setor público: a experiência do Contrato Programa nos hospitais da administração direta no Estado de São Paulo [Tese de Doutorado]. São Paulo: Escola de Administração de Empresas de São Paulo, Fundação Getúlio Vargas; 2012.

15. Pinto NRS, Tanaka OY, Spedo SM. Política de saúde e gestão no processo de (re)construção do SUS em município de grande porte: um estudo de caso de São Paulo, Brasil. Cad Saúde Pública 2009; 25: 927-38.

16. Pahim MLL. Organizações Sociais de Saúde do Estado de São Paulo: inserção privada no SUS e gestão financeira do modelo pela Secretaria de Estado da Saúde [Tese de Doutorado]. São Paulo: Faculdade de Medicina, Universidade de São Paulo; 2009.

17. Coordenação de Atenção Básica, Secretaria Municipal de Saúde de São Paulo. Lista de unidades gerenciadas por parceiras sob convênio. São Paulo: Secretaria Municipal de Saúde de São Paulo; 2010.

18. Núcleo Técnico de Contratação de Serviços de Saúde, Secretaria Municipal de Saúde de São Paulo. Contratos de gestão: unidades sob gerenciamento pela Organização Social. 2010.

19. Coordenação da Atenção Básica, Secretaria Municipal de Saúde de São Paulo. Instrumento normativo; normas para o monitoramento técnico e administração dos recursos financeiros da ESF/convênios. São Paulo: Secretaria Municipal de Saúde de São Paulo; 2008.
20. Câmara Municipal de São Paulo. Relatório final da subcomissão criada para analisar e acompanhar a execução dos contratos firmados pela municipalidade com as Organizações Sociais na área da saúde. São Paulo: Câmara Municipal; 2011.

21. Instituto Brasileiro de Geografia e Estatística. As entidades de assistência social privadas sem fins lucrativos no Brasil 2006. Rio de Janeiro: Instituto Brasileiro de Geografia e Estatística; 2007.

22. Oliveira RR. Os conceitos de regulação em saúde no Brasil [Dissertação de Mestrado]. São Paulo: Faculdade de Medicina, Universidade de São Paulo; 2010.

23. Secretaria Executiva de Comunicação, Prefeitura Municipal de São Paulo. Prefeitura entrega duas unidades de saúde na zona sul. http://www.pre feitura.sp.gov.br/portal/a_cidade/noticias/index. php?p=6390 (acessado em 25/Out/2011).

24. Carneiro Jr. N. O setor público não estatal: as Organizações Sociais como possibilidades e limites na gestão pública da saúde [Tese de Doutorado]. São Paulo: Faculdade de Medicina, Universidade de São Paulo; 2002.

25. Valor Econômico. Ranking nacional das maiores empresas do setor de serviços médicos. http://www. valor.com.br/valor1000/2013/ranking1000maio res/Serviços_Médicos (acessado em 13/Dez/2013).

Recebido em 25/Fev/2014

Versão final reapresentada em 25/Jul/2014

Aprovado em 05/Ago/2014 